Published in final edited form as:

Semin Oncol Nurs. 2010 February ; 26(1): 47-58. doi:10.1016/j.soncn.2009.11.007.

\title{
Technology and Quality of Life Outcomes
}

\author{
Eileen Danaher Hacker, PhD, APN, AOCN \\ Clinical Associate Professor, University of Illinois at Chicago, College of Nursing, Department of \\ Biobehavioral Health Science
}

\begin{abstract}
Objectives-To discuss recent technological advances in quality of life data collection and guidance for use in research and clinical practice. The use of telephone-, computer-, and web/Internet based technologies to collect quality of life data, reliability and validity issues, and cost will be discussed along with the potential pitfalls associated with these technologies.
\end{abstract}

Data Sources-Health care literature and web resources.

Conclusion-Technology has provided researchers and clinicians with an opportunity to collect QOL data from patients that were previously not accessible. Most technologies offer a variety of options, such as language choice, formatting options for the delivery of questions, and data management services. Choosing the appropriate technology for use in research and/or clinical practice primarily depends on the purpose for QOL data collection.

Implications for Nursing Practice-Technology is changing the way nurses assess quality of life in patients with cancer and provide care. As stakeholders in the health care delivery system and patient advocates, nurses must be intimately involved in the evaluation and use of new technologies that impact quality of life and/or the delivery of care.

Over the past 20 years, society has witnessed an explosion in technology that continues to evolve and is changing the way we report, collect and/or access patient information, such as quality of life outcomes. Over 600 instruments are currently available to assess quality of life (QOL); most self-administered or administered by an interviewer.1 Factors such as severity of illness and low literacy levels impede the patients' ability to provide QOL. Clinicians experience difficulty administering, scoring and interpreting instruments in the clinical setting. 2 Lack of resources, lack of understanding regarding the concept of QOL and missing data are examples of problems encountered by researchers.3 Advances in technology, such as personal digital assistants (PDAs), interactive voice response (IVR) systems, computers and the Internet, have made it possible to address some of the obstacles associated with traditional approaches for assessing QOL. This article will provide an introduction to recent technological advances in QOL data collection, as well as practical guidance for use in research and clinical practice. In addition, technological advancements in the use of Internet sites for providing information and even support to cancer patients will be discussed, along with the potential pitfalls associated with these technologies.

(C) 2009 Elsevier Inc. All rights reserved.

Eileen Danaher Hacker, University of Illinois at Chicago, College of Nursing, Department of Biobehavioral Health Science, 845 S.

Damen Avenue, Chicago, IL 60612, ehacker@uic.edu.

Publisher's Disclaimer: This is a PDF file of an unedited manuscript that has been accepted for publication. As a service to our customers we are providing this early version of the manuscript. The manuscript will undergo copyediting, typesetting, and review of the resulting proof before it is published in its final citable form. Please note that during the production process errors may be discovered which could affect the content, and all legal disclaimers that apply to the journal pertain. 


\section{Quality of Life}

Quality of life, a frequently used term, has been defined in numerous ways in the cancer literature. While no gold standard exists for defining QOL, one of the most frequently cited defines QOL as "a state of well being that is a composite of two components: (1) the ability to perform everyday activities that reflect physical, psychological, and social well being and (2) patient satisfaction with levels of functioning and the control of disease and/or treatmentrelated symptoms."

A wide range of outcomes have been used to represent QOL outcomes in people with cancer. These outcomes include symptoms, functional status, general health perceptions, and quality of life. Although no consensus has been reached regarding the definition and/or measurement of QOL outcomes, there are two major areas of theoretical agreement: (1) the individual is the most suitable judge of his/her own QOL; and (2) QOL is multidimensional, encompassing all aspects of a person's life. ${ }^{7-} 9$ For the purposes of this article, QOL will include all of these potential outcomes as long as the information is self-reported and falls within one of the these broad categories of symptoms, functional status, general health perceptions or quality of life. For an indepth review of quality of life outcomes, the reader is referred to the Revised Wilson and Cleary Conceptual Model of Patient Outcomes.5, 6 This model is particularly useful for categorizing various health outcomes that have been used to assess QOL $^{6}$ (See Figure 1, page ? in Ferrans' article elsewhere in this issue). A plethora of instruments to measure QOL outcomes exist and these instruments may be administered in a variety of formats, such as traditional pencil-and-paper approaches, or less traditional formats, such as IVR technology.

\section{Technology Advances in Quality of Life Data Collection}

The technology explosion has changed the health care environment. Today, health care workers equipped with mobile office technology, such as laptops, blackberries, cellular phones, and PDAs, can access data or information 24 hours a day from almost any remote location within the range of the device's wireless capacity. The potential applications of these technological advances for collecting QOL information continue to rapidly evolve and may help researchers and clinicians gain access to self-report information in people who were previously not readily accessible. Several platforms for collecting QOL data are currently available and can be categorized as (1) telephone-based; (2) computer-based; or, (3) web/Internet-based. Telephone-based technology uses computer applications to gather QOL data through landlines or cellular phones. Computer-based technology refers to computerized applications to collect QOL data installed on stand-alone computer devices so that the person of interest can evaluate and directly input their own QOL information. Web/Internet-based technology collects QOL information directly from the person of interest through a web-based program accessed on an Internet-ready computerized device. Table 1 displays the general benefits/ optimal uses and limitations of the three categories, which will be discussed in the following sections.

\section{Telephone-Based Technology}

\section{Overview of the technology}

IVR technology, used extensively in America, employs an automated, telephone-based technology that allows telephone users to interact with a computer through voice recognition or keypad input detection. This technology works with any type of touch-tone telephone, whether land-band or cellular. Initiation of an IVR system occurs when telephone users call into the system. Conversely, potential responders may be called directly by the system if it is programmed to do so. Telephone users typically navigate through the system by responding to questions and selecting options from a voice menu. Several formats for delivering questions 
are available, such as delivering questions in a specific order, randomly delivering questions and/or branching questions based on responses. Access to IVR systems is generally available 24 hours a day/7 days a week. IVR systems may be set up to provide questions and responses in multiple languages, thereby providing accessibility to people who speak a variety of languages. Because this technology is computerized, responses to questions may be collated, organized, and analyzed according to predetermined criteria set by researchers and/or clinicians. For instance, researchers who are interested in group-level data may configure the system to receive reports about group-level responses. Conversely, clinicians who are interested in individual responses may configure the system to receive alerts regarding patients who cross a predefined threshold indicating a need for medical attention.

\section{Using IVR technology for QOL data collection}

Traditional paper-and-pencil questionnaires may be reconfigured into an IVR format so that the questionnaire can be administered via a telephone system. Whereas the traditional paperand-pencil approach requires the individual to read the question and select the most appropriate response, IVR technology requires the individual to listen to questions over the telephone and respond verbally or by selecting the corresponding key on the touch-tone telephone. A search of the Patient Reported Outcomes and Quality of Life Instruments Database (PROQOLIDC) ${ }^{1}$ revealed several instruments that are currently available to be administered via an IVR system although none specifically address quality of life in people with cancer. Other QOL instruments using IVR systems may be currently available but not listed in this extensive database. For example, EuroQol, an international group of QOL researchers, recently entered into a license agreement with Perceptive Informatics to provide an IVR version of the EQ-5D.7 The EQ-5D is a widely used QOL instrument and conversion of the paper to an IVR format illustrates the potential appeal of IVR technology to gather QOL data.

In people with cancer, IVR technology has been used for a multitude of purposes, such as collecting symptom data and generating symptom alerts to providers, ${ }^{8}$ categorizing the patterns of symptoms over time, ${ }^{9}$ delivering cancer screening advice, 10,11 and delivering symptom management strategies.12-14 Because this technology is widely accessible and familiar to the general public, the potential applications for collecting QOL data and delivering interventions to improve QOL are vast. One of the earliest studies using IVR technology examined the use of a computer-automated telephone outreach system to monitor the concrete needs (e.g., transportation needs and assistance with activities of daily living) of people with cancer ( $\mathrm{n}=$ 97) receiving outpatient chemotherapy. 15 The results from this early study indicated that IVR technology had the potential to be a time-, labor- and cost-efficient strategy to monitor and address the ongoing needs of large numbers of patients. A more recent study compared the effects on symptom management of a nurse-assisted symptom management (NASM) cognitive-behavioral intervention to automated telephone symptom management (ATSM). 13 Patients in both arms were contacted six times over an eight-week period. The automated telephone symptom management arm (the IVR arm), resulted in improved management of anxiety, depression, poor appetite, cough, and fatigue, while the nurse-assisted symptom management arm was more successful in managing cancer pain.

\section{Reliability and validity issues}

As more QOL instruments become available using IVR technology, there will be an increased need to demonstrate data equivalency, reliability, and validity as the mode of administration may impact the psychometrics of the instrument. For instance, studies need to be conducted to determine data equivalency of responses when the visual cues typically associated with pen and paper instruments are replaced with auditory cues in IVR technology. In addition, the formatting of responses may impact usability of a QOL instrument in an IVR format, particularly if the responses are wordy, and impede understanding. Instruments using a numeric 
rating scale, such as the M.D. Anderson Symptom Inventory, may be more amendable for conversion into an IVR format because of the ease of brevity of responses and ease of translation. ${ }^{16}$ Table 2 depicts two separate IVR scripts; one using a numerical rating scale and another using wordy responses to illustrate some of the potential differences.

Cost

The cost for implementing IVR technology to collect QOL data is variable and depends upon the services required, such as volume of calls to be handled and whether the application supports voice recognition in addition to keypad input detection. Contracting with an outside company to outsource IVR may be more cost-effective than purchasing a system, particularly if the services are only needed on a short-term basis. A basic IVR system can be purchased for approximately $\$ 3000$ to $\$ 8000$. More advanced systems with high-end technology can cost upwards of $\$ 100,000$. IVR technology services are available from multiple vendors, such as Healthcare Technology Systems, Inc. (Madison, WI), Voxeo (Orlando, FL), or Datatel Communication Technologies (Weston, FL) to help researchers and clinicians adapt this technology to meet their needs for assessing QOL. Given the expected growth in popularity of IVR technology for health care research and clinical services, the number of vendors available will undoubtedly continue to grow.

\section{Computer-Based Technology}

\section{Overview of the technology}

Computer-based technology to collect data requires responders to interact directly with a standalone computer through a touch screen or keypad input detection. Like IVR technology, options for computer-based technology include choice of languages, ability to format delivery of questions in various ways, and systems to alert clinicians of abnormal patient reports. Most computerized devices will collate, organize, and analyze according to the researchers' or clinicians' predetermined criteria, if programmed to do so. The capacity for collecting data 24 hours a day/7 days a week is also available, however, this may be limited by the choice of the computerized device. For instance, stand-alone computers in a clinic setting will only be accessible during clinic hours compared to a hand held PDA which, if given to the patient, can be accessible 24 hours a day.

Multiple computer formatting options are available and may be incorporated into computerized collection of self-report data. Usability should be the primary concern, and formatting options, such as user interface and operation, need to be developed in response to the unique needs of the population of interest. Large font sizes and mid-tone colors are generally preferred.17 Questions may be displayed one question at a time on the screen, or several questions displayed concurrently. One question per screen minimizes scrolling and increases focus on the individual question; 18 however, multiple items per screen reduces completion time and the number of keystrokes. ${ }^{19}$ While most computerized questionnaires are visual in nature (displayed on the computer screen), an audio component may be added so that users can see as well as hear the questions and responses. Adding an audio component is particularly helpful for those with low literacy rates, vision difficulties or inexperience with computers. ${ }^{20}$ Another available formatting option is to install an alert system to notify people completing the questionnaires of unanswered questions, giving responders an additional opportunity to answer missed questions. This type of alert system potentially reduces the amount of missing data, a particularly appealing option for improving the quality of data collection processes.21, 22

\section{Using computer-based technology for QOL data collection}

Health care providers and researchers interested in patient-reported outcomes, such as QOL, are now applying computer technologies to obtain this much-needed information. Like IVR 
systems, a psychometrically sound paper version of a QOL instrument is typically adapted for use on a computer device. A number of reliable and valid paper-and-pencil QOL questionnaires have been converted for use in a computerized format. The PROQOLID $\odot$ lists a total of 10 generic and disease-specific instruments.1 In people with cancer, other computerized QOL instruments have been reported in the literature, such as the EORTC QLQ-C30,23, 24 University of Washington Quality of Life Questionnaire, ${ }^{25}$ and Functional Assessment of Quality of Life (FACT) ${ }^{26,} 27$ As more researchers and clinician shift to computerized collection of data, the number of QOL instruments converted from a paper-and-pencil format to a computerized version will continue to grow.

QOL questionnaires may be installed on a variety of computerized devices, such as stationary desktops, notebooks/laptops, PDAs, cellular phones or even subjective markers of wrist actigraphs. Because of the mobility of at least some of these computerized devices, QOL data may be gathered in a variety of settings, including the user's natural environment. Choosing a device depends on the needs and ability of the users as well as the purposes of QOL data collection. For instance, a stationary desktop may be the most appropriate choice in a clinic setting when QOL information is being collected to monitor the patient's response to treatment. Conversely, researchers interested in evaluating changes in QOL over time may chose a smaller device, such as a PDA, to gather data over multiple time points in the user's natural environment.

The ability to capture data in real time in the patient's natural environment, as opposed to only in the health care setting, is one of the major advantages of using a computerized approach. The subjective event marker (Figure 1) of a wrist actigraph is one example of a computer device that can be used to collect real-time data in the patient's natural environment. We have successfully used this subjective event marker as a 1-item symptom rating scale to collect repeated self-reported measurements of fatigue throughout the day. ${ }^{28,}{ }^{29}$ Hematopoietic stem cell transplant patients rated their fatigue intensity three times a day over five days before admission to the hospital for the transplant and during the immediate post-transplant period, when they were experiencing the acute toxicities associated with the high-dose chemotherapy. Even though their fatigue increased substantially as they became acutely ill, the majority of patients continued to provide the fatigue ratings. Real-time data collection of quality of life outcomes is particularly attractive in the clinical setting, if the data can be used to guide clinical decision making.

Although data collection in real time can be accomplished using paper versions, improved patient compliance has been documented with computerized compared to paper diaries. ${ }^{30}$ Computerized real-time data collection may be preferable over paper diaries due to the ability to date- and time-stamp data entries in an objective manner. Paper diaries may not be a reliable source of information as patients may hoard the diaries, completing them in one sitting on the basis of their memory as opposed to the real-time experience.

The time it takes to complete computerized QOL questionnaires is an important consideration, particularly if it is to be adopted in busy clinical settings. A study of head and neck cancer patients $(n=196)$ reported that it took an average of 9 minutes to complete three questionnaires (EORTC QLQ-C30, EORTC-HN, and the Hospital Anxiety and Depression Scale). The investigators considered the time to completion adequate, as head and neck health care providers previously reported that QOL questionnaires should take no more than 10 minutes. ${ }^{31}$ A more recent study of 342 cancer patients examined the acceptability of asking symptom and quality-of-life questions using the Electronic Self Report Assessment-Cancer program on touch screen, wireless laptops. 18 Patients completed questionnaires in the clinic or examination rooms within an average of 15 minutes. Time and resource constraints have been cited as potential barriers for implementing computerized collection of quality of life data, therefore it 
is imperative that potential stakeholders, such as patients, nurses and physicians, have adequate opportunity to evaluate new data collection processes. 32

One of the more novel developments associated with computer-based technology is the ability to use computer-adaptive testing for QOL assessments. Unlike static paper-and-pencil QOL questionnaires, computerized assessments of QOL permit branching of questions, generally referred to as computer-adaptive testing, so that the types and/or order of questions depend on responses to previous questions. This individualized approach allows respondents to answer only those questions considered appropriate, given their health status and personal situation. Most computer-adaptive testing programs for QOL assessment rely on item response theory to model patient-reported outcomes, such as QOL. While item response theory and computeradaptive testing are exciting developments, issues such as the need for research into their limitations still remain. ${ }^{33} \mathrm{An}$ in-depth discussion of item response theory and patient-reported outcomes is beyond the scope of this article. The reader is referred to a series of articles published in the August (2007) supplement of Quality of Life Research for a more extensive review.

\section{Reliability and validity issues}

The mode of administration (paper vs. computer) potentially impacts the psychometric properties of the QOL instrument; therefore, it is vitally important that reliability and validity testing occurs. Several studies compared paper-and-pencil administration of QOL instruments to computer administration. ${ }^{34-} 39$ One early study evaluated the acceptability, reliability and consistency of a computerized version of the EORTC QLQ-C30.39 The patients reported that the computerized version of the EORTC was acceptable in terms of providing QOL information to oncology health care providers. Data from the computer administration correlated highly with the paper-and-pencil administration, and internal consistencies for both modes of administration were similar.

Similar results for other QOL instruments have been reported when comparing paper administration to computer administration. In a study of 152 prostate cancer patients examining the reliability, validity, and feasibility of using PDAs compared to paper versions of the International Prostate Symptom Score (IPSS), the Patient Oriented Prostate Cancer Utility Survey (PORPUS), and the International Index of Erectile Function-5 (IIEF-5), similar internal consistencies were demonstrated for both the PDA and paper-and-pencil versions of the instruments. ${ }^{35}$ The computerized versions also demonstrated adequate test-retest reliability. Data from both modes of administration were highly correlated. However, the PDA version provided the added advantage of lower missing response rates compared to the paper version. In addition, $82 \%$ of patients preferred either PDAs or had no preference for PDA or paper-andpencil versions.

Not all studies found equivalence when comparing computerized QOL instruments to paper versions; therefore, a mode of administration effect may be present. In a study evaluating the use of the computer versus paper administration of the Center for Epidemiologic Studies Depression Scale (CES-D), higher scores were reported on the paper version when the paper version was administered before the computer version. ${ }^{34}$ This suggests that reliability and validity testing of newly converted computerized questionnaires must be undertaken to ensure adequate psychometric properties.

\section{Cost}

Initiating computerized QOL data collection can be a costly endeavor, specifically the upfront costs during the implementation phase. Factors that influence overall costs include choice of a computerized device choice, number of devices needed, and amount of data to be stored. 
Like IVR technology, all of the computerized devices have the capacity to store data, although some devices have limited storage capabilities, requiring more frequent downloading of data and/or shorter collection times. PDAs, generally considered less costly compared to standalone desktops, may be more cost-effective for collecting data long-term in the subject's natural environment. However, these costs may be offset by the number of PDA devices needed if each patient is given their own device. On the other hand, stand-alone laptops may be more cost-effective for a clinic setting if only a few devices are required to adequately capture the data.

\section{Web/Internet-Based Technologies}

\section{Overview of the technology}

Web/Internet-based technologies to collect patient-reported outcomes are comparable to computer-based technologies in that the person of interest interacts directly with the computer to provide self-reported information. The major difference is that web/Internet-based technologies allow the individual to access the questionnaire from any Internet-ready device, including the patient's personal computer. Over 121 million homes and businesses in the United States are currently connected to the Internet, with high-speed service subscribers in all 50 states and nearly $100 \%$ of zip codes. ${ }^{40}$ Because of widespread availability, health care researchers and clinicians increasingly are using Web-based technologies to collect self-report data, such as QOL outcomes. ${ }^{41-46}$

The formatting options for web/Internet-based technologies are very similar to computerized formats addressed previously. Researchers and/or clinicians must consider a variety of factors, including usability, availability of Internet-ready computer devices, acceptability of electronic data collection to patients and clinicians, and subject/provider burden, such as time requirements. Collecting QOL data electronically through the Internet offers several benefits, such as the ability to collect data in real-time and send alerts to health care providers if predetermined thresholds are crossed. Internet-based technologies have the added benefit of being able to collect data or monitor patients across diverse locations, simultaneously. This ability to collect data from a wide variety of geographic locations is particularly appealing for conducting large, multi-site clinical trials involving diverse geographic areas.

\section{Using web/Internet-based technology for QOL data collection}

Researchers and clinicians have used the Internet to capitalize on these potential advantages when collecting QOL data in patients with cancer. For instance, monitoring patient symptoms following chemotherapy administration is one of the most important functions of an oncology practitioner and a requirement for those enrolled in cancer clinical trials. Unfortunately, many of the side effects associated with chemotherapy occur while the patient is at home and not under direct medical supervision. To address this issue, an interdisciplinary group from Memorial Sloan-Kettering developed and tested an online patient self-reporting system of chemotherapy toxicities based on the National Cancer Institute's Common Terminology Criteria for Adverse Events. 45,46 This system allows patients to log on to a touch screen computer during scheduled clinic visits to provide information regarding chemotherapy toxicities; this information is then shared with practitioners during office visits. Patients are also given the opportunity to voluntarily $\log$ in to the system at home to provide the same information. More than $85 \%$ were compliant with self-reporting of toxicities during scheduled clinic visits, and approximately $66 \%$ voluntarily logged on to the system while at home, demonstrating the feasibility of using the Internet to self-report chemotherapy toxicities. Patient and clinician acceptance of the self-reporting system was high. Adjustments in chemotherapy administration (treatment delays, dose adjustments, and scheduling changes) occurred as a result of alerts generated by patient-reported toxicities. 
Although this study demonstrated successful outcomes, it is not known if Internet reporting of QOL data directly to health care professionals will result in positive clinical outcomes in all situations, particularly when patients become seriously ill. ${ }^{48}$ For instance, local computer and/ or server malfunctions, breaches of confidentiality, inability on the part of the health care professionals to retrieve real-time reports in a timely manner, or an unwillingness on the part of patients to enter sensitive information into a Web-based program may lead to breakdowns in patient-provider communications. Readers are referred to Jones and colleagues' extensive review of issues related to Internet-based systems for collecting patient-reported outcomes. ${ }^{2}$ Further research and exploration of the applicability of Internet-based applications are required before widespread dissemination into clinical practice. Several internet-based programs for collecting patient reported outcomes, such as quality of life, currently exist or are in the process of being tested for use in patients with cancer. ${ }^{41,49-51}$

The Patient-Reported Outcomes Measurement Information System (PROMIS) initiative, sponsored by the National Institutes of Health, represents one of the most comprehensive efforts to develop a computer-adaptive testing system for the collection of patient-reported outcomes to be used in clinical research and practice. ${ }^{53}, 54$ The charge of this initiative is to develop and test a large bank of items representing patient-reported outcomes, create a computer-adaptive testing system, and design a publicly available system that will be made available to clinical researchers to access the patient-reported outcomes item bank and computer-adaptive tests.55 A number of PROMIS instruments are currently available in short forms or as item banks for use in computer-adaptive testing (Table 3). These instruments are considered valid for Internet/electronic administration or administration on a personal computer-based application. Further testing is needed to determine if the results from electronic administration of PROMIS instruments compare to paper-and-pencil administration.

\section{Reliability and validity issue}

All of the issues that pertain to computer-based reliability and validity issues also pertain to Internet-based technology as the mode of administration (computer administered) is similar. Instruments that have established reliability and validity for computer-administration should be adequate for Internet-based administration of questionnaires.

\section{Cost}

The programming costs for Internet-based collection of QOL data is also very similar to computer-based technologies although the hardware costs may actually be lower as patients are able to access the questionnaires on any Internet-ready device. This means that researchers and clinicians may not have to provide computer access in order to complete the QOL questionnaires. Patients can use their own computer devices, such as home personal computers, blackberries, or even cell phones, to complete QOL data collections as long as they are Internet ready. Other costs for web/Internet-based technologies may include programmer costs and central hardware needs.

\section{Use of the Internet as a Source for QOL Information}

In addition to collecting QOL data, the Internet is frequently used as a source of information to address health care needs, including cancer. A Google search of "cancer information" resulted in 38,700,000 listings in 0.12 seconds. This large number of listings can be overwhelming for people who may or may not be familiar with browsing the Internet for information. Fortunately, all of the initial listings were from reputable and professionally reviewed sites, such as the National Cancer Institute and the American Cancer Society. Unfortunately, many non-professionally reviewed sites can be easily accessed, and the lay person may not be able to differentiate reputable from disreputable sources of information. 
Patients and their families may also turn to blogs, chat rooms, or social networking sites such as Twitter or Facebook for information related to cancer and/or QOL. While these may be a source of support for some patients, visiting these sites, many of which are not monitored by health care professionals, may also become a source of stress for patients who are not able to tease out unsubstantiated statements or claims. As Internet use continues to expand, health care professionals need to be aware of some of the pitfalls associated with information-seeking behaviors on the Internet. The best recommendation may be to advise patients of the benefits and risks of using the Internet to access health care information. Table 4 provides some helpful hints for browsing the Internet for cancer information. Patients should be strongly encouraged to clarify information with their own health care provider.

\section{Electronic Health Records}

Electronic medical records and electronic health records may be another source of QOL information. These two terms are frequently used interchangeably although distinct differences exist. Electonic medical records refer to the computerized record of an individual's health within a specific health care delivery system. An electronic health record is broader and refers to a longitudinal record of an individual's health information that includes information from a number of health care delivery systems stored in a digitalized format. Electronic medical records are typically owned by the organization that provided the care but can be accessed by the individual if so requested. Conversely, electronic health records are owned by the individual and may be shared among health care delivery systems provided the individual approves the sharing of information.

A recognized need exists to develop and promote the use of health information technology that will potentially improve the quality of health care by expanding access as well as making health care safer, more effective and efficient. ${ }^{56}$ Implementation of these electronic technologies has been slow. A recent survey to assess the use of electronic medical records among physicians $(\mathrm{n}=2,758)$ in ambulatory settings found that only $17 \%$ had adopted an electronic records system. ${ }^{57}$ Capital costs, inability to find a system to meet the needs of the practice, concern regarding return on investment, and worry about the system becoming obsolete were cited as major barriers. President Barack Obama recently signed the American Recovery and Reinvestment Bill of 2009 that includes a $\$ 19$ billion investment to stimulate the adoption of health information technology. Major efforts will be directed toward the development and implementation of electronic health records. These electronic health records may have the capacity to include, among other things, information about patient-reported outcomes, such as QOL.

\section{Conclusion}

The technology explosion has provided researchers and clinicians with an opportunity to collect QOL data from patients that were previously not accessible. The three broad technology categories, (telephone-, computer-, and web/Internet-based technologies) share several similar benefits, such as ability to choose a language, ability to choose formatting options for the delivery of questions and ability to send medical alerts to the health care providers if desired. In addition, most computers will collate, organize and analyze QOL data if programmed accordingly. There are several distinct advantages for each of the technological categories. For example, telephone services (either land-lines or cellular) have widespread availability making telephone-based technologies highly accessible to almost all patients. Computerized devices are now manufactured in a variety of shapes and sizes, making this category highly flexible for meeting the needs of broad categories of patients. Web/Internet based technology has the capacity to reach diverse populations in a variety of geographic locations. Computer- and internet-based technologies allow for audio as well as visual cues when collecting QOL 
information. Choosing the appropriate technology for use in research and/or clinical practice primarily depends on the purpose for QOL data collection. Choosing a system wisely is imperative as implementing computerized QOL data collection involves significant start-up costs. Technology is changing the way nurses assess quality of life in people with cancer and provide care. As stakeholders in the health care delivery system and patient advocates, nurses must be intimately involved in the evaluation and use of new technologies that impact quality of life and/or the delivery of care.

\section{Acknowledgments}

This work was supported with funding from the National Institutes of Health, National Institute of Nursing Research (PI, E. Hacker; K01 NR009375).

\section{REFERENCES}

1. Mapi Research Institute. Patient Reported Outcomes and Quality of Life Instruments Database.

2. Jones JB, Snyder CF, Wu AW. Issues in the design of Internet-based systems for collecting patientreported outcomes. Qual Life Res 2007;16(8):1407-1417. [PubMed: 17668293]

3. Bottomley A, Vanvoorden V, Flechtner H, Therasse P. The challenges and achievements involved in implementing Quality of Life research in cancer clinical trials. Eur J Cancer 2003;39:275-285. [PubMed: 12565977]

4. Gotay CC, Korn EL, McCabe MS, Moore TD, Cheson BD. Quality-of-life assessment in cancer treatment protocols: research issues in protocol development. J Natl Cancer Inst 1992;84:575-579. [PubMed: 1556768]

5. Wilson IB, Cleary PD. Linking clinical variables with health-related quality of life. A conceptual model of patient outcomes. JAMA 1995;273:59-65. [PubMed: 7996652]

6. Ferrans CE, Zerwic JJ, Wilbur JE, Larson JL. Conceptual model of health-related quality of life. J Nurs Scholarsh 2005;37:336-342. [PubMed: 16396406]

7. Perceptive Informatics enters license agreement with EuroQoL group to provide enhanced standardization for ePRO solution. Perspective Infomatics. 2009 [Accessed June 10, 2009]. at http://www.perceptive.com/news/Press-Release.html?id=324

8. Mooney KH, Beck SL, Friedman RH, Farzanfar R. Telephone-linked care for cancer symptom monitoring: a pilot study. Cancer Pract 2002;10:147-154. [PubMed: 11972569]

9. Brown CG, Beck SL, Peterson DE, McGuire DB, Dudley WN, Mooney KH. Patterns of sore mouth in outpatients with cancer receiving chemotherapy. Support Care Cancer 2009;17:413-428. [PubMed: 18839221]

10. Corkrey R, Parkinson L, Bates L. Pressing the key pad: trial of a novel approach to health promotion advice. Preventive Med 2005;41:657-666.

11. Corkrey R, Parkinson L, Bates L, Green S, Htun AT. Pilot of a novel cervical screening intervention: interactive voice response. Australian and New Zealand journal of public health 2005;29(3):261264. [PubMed: 15991775]

12. Sikorskii A, Given CW, Given B, et al. Symptom management for cancer patients: a trial comparing two multimodal interventions. Journal of pain and symptom management 2007;34(3):253-264. [PubMed: 17618080]

13. Sikorskii A, Given CW, You M, Jeon S, Given BA. Response analysis for multiple symptoms revealed differences between arms of a symptom management trial. J Clin Epidemiol 2009;62(7):716-724. [PubMed: 19124223]

14. Given CW, Sikorskii A, Tamkus D, et al. Managing symptoms among patients with breast cancer during chemotherapy: results of a two-arm behavioral trial. J Clin Oncol 2008;26(36):5855-5862. [PubMed: 19029420]

15. Christ G, Siegel K. Monitoring quality-of-life needs of cancer patients. Cancer 1990;65(3 Suppl): 760-765. [PubMed: 2302653]

16. Cleeland CS, Mendoza TR, Wang XS, et al. Assessing symptom distress in cancer patients: the M.D. Anderson Symptom Inventory. Cancer 2000;89(7):1634-1646. [PubMed: 11013380] 
17. Kinzie MB, Cohn WF, Julian MF, Knaus WA. A user-centered model for web site design: needs assessment, user interface design, and rapid prototyping. J Am Med Inform Assoc 2002;9(4):320 330. [PubMed: 12087113]

18. Wolpin S, Berry D, Austin-Seymour M, et al. Acceptability of an Electronic Self-Report Assessment Program for patients with cancer. Comput Inform Nurs 2008;26(6):332-338. [PubMed: 19047882]

19. Toepoel V, Das M, Van Soest A. Effect of design in web surveys: Comparing trained and fresh respondents. Public Opinion Quarterly 2008;72(5):985-1007.

20. Hahn EA, Cella D, Dobrez D, et al. The talking touchscreen: a new approach to outcomes assessment in low literacy. Psycho-oncology 2004;13(2):86-95. [PubMed: 14872527]

21. Wilson AS, Kitas GD, Carruthers DM, et al. Computerized information-gathering in specialist rheumatology clinics: an initial evaluation of an electronic version of the Short Form 36. Rheumatology (Oxford, England) 2002;41(3):268-273.

22. Hanscom B, Lurie JD, Homa K, Weinstein JN. Computerized questionnaires and the quality of survey data. Spine 2002;27(16):1797-1801. [PubMed: 12195074]

23. Velikova G, Wright EP, Smith AB, et al. Automated collection of quality-of-life data: a comparison of paper and computer touch-screen questionnaires. J Clin Oncol 1999;17(3):998-1007. [PubMed: 10071295]

24. Allenby A, Matthews J, Beresford J, McLachlan SA. The application of computer touchscreen technology in screening for psychosocial distress in an ambulatory oncology setting. European journal of cancer care 2002;11(4):245-253. [PubMed: 12492461]

25. Millsopp L, Frackleton S, Lowe D, Rogers SN. A feasibility study of computer-assisted health-related quality of life data collection in patients with oral and oropharyngeal cancer. International journal of oral and maxillofacial surgery 2006;35(8):761-764. [PubMed: 16697148]

26. Gil KM, Frasure HE, Hopkins MP, Jenison EL, von Gruenigen VE. Effect of method of administration on longitudinal assessment of quality of life in gynecologic cancer: an exploratory study. Health and quality of life outcomes 2005;3:6. [PubMed: 15655074]

27. Janda M, DiSipio T, Hurst C, Cella D, Newman B. The Queensland Cancer Risk Study: general population norms for the Functional Assessment of Cancer Therapy-General (FACT-G). Psychooncology 2009;18(6):606-614. [PubMed: 18942661]

28. Hacker ED, Ferrans C, Verlen E, et al. Fatigue and physical activity in patients undergoing hematopoietic stem cell transplant. Oncol Nurs Forum 2006;33(3):614-624. [PubMed: 16676017]

29. Hacker ED, Ferrans CE. Ecological momentary assessment of fatigue in patients receiving intensive cancer therapy. J Pain Symptom Manage 2007;33(3):267-275. [PubMed: 17349496]

30. Stone AA, Shiffman S, Schwartz JE, Broderick JE, Hufford MR. Patient compliance with paper and electronic diaries. Controlled clinical trials 2003;24(2):182-199. [PubMed: 12689739]

31. Mehanna HM, Morton RP. Why are head and neck cancer clinicians not measuring quality of life? The Journal of laryngology and otology 2006;120(10):861-864. [PubMed: 16707035]

32. Morris J, Perez D, McNoe B. The use of quality of life data in clinical practice. Qual Life Res 1998;7 (1):85-91. [PubMed: 9481154]

33. Fayers PM. Applying item response theory and computer adaptive testing: the challenges for health outcomes assessment. Qual Life Res 2007;16:187-194. [PubMed: 17417722]

34. Swartz RJ, de Moor C, Cook KF, et al. Mode effects in the center for epidemiologic studies depression (CES-D) scale: personal digital assistant vs. paper and pencil administration. Qual Life Res 2007;16 (5):803-813. [PubMed: 17295102]

35. Matthew AG, Currie KL, Irvine J, et al. Serial personal digital assistant data capture of health-related quality of life: a randomized controlled trial in a prostate cancer clinic. Health and quality of life outcomes 2007;5:38. [PubMed: 17617906]

36. Fortner B, Okon T, Schwartzberg L, Tauer K, Houts AC. The Cancer Care Monitor: psychometric content evaluation and pilot testing of a computer administered system for symptom screening and quality of life in adult cancer patients. Journal of pain and symptom management 2003;26(6):10771092. [PubMed: 14654260]

37. Kleinman L, Leidy NK, Crawley J, Bonomi A, Schoenfeld P. A comparative trial of paper-and-pencil versus computer administration of the Quality of Life in Reflux and Dyspepsia (QOLRAD) questionnaire. Medical care 2001;39(2):181-189. [PubMed: 11176555] 
38. Schaeren S, Bischoff-Ferrari HA, Knupp M, Dick W, Huber JF, Theiler R. A computer touch-screen version of the North American Spine Society outcome assessment instrument for the lumbar spine. The Journal of bone and joint surgery 2005;87(2):201-204.

39. Taenzer PA, Speca M, Atkinson MJ, et al. Computerized quality-of-life screening in an oncology clinic. Cancer Pract 1997;5(3):168-175. [PubMed: 9171553]

40. High speed services for internet access: Status of of December 31, 2007. Industry Analysis \& Technology Division, Wireline Competition Bureau, Federal Communications Commission. 2009 [Accessed June 15, 2009]. at http://hraunfoss.fcc.gov/edocs_public/attachmatch/DOC-287962A1.pdf

41. Berry DL, Trigg LJ, Lober WB, et al. Computerized symptom and quality-of-life assessment for patients with cancer part I: development and pilot testing. Oncology nursing forum 2004;31(5):E75E83. [PubMed: 15378104]

42. Bliven BD, Kaufman SE, Spertus JA. Electronic collection of health-related quality of life data: validity, time benefits, and patient preference. Qual Life Res 2001;10(1):15-22. [PubMed: 11508472]

43. Fann JR, Berry DL, Wolpin S, et al. Depression screening using the Patient Health Questionnaire-9 administered on a touch screen computer. Psycho-oncology 2009;18(1):14-22. [PubMed: 18457335]

44. Basch E, Goldfarb S. Electronic patient-reported outcomes for collecting sensitive information from patients. The journal of supportive oncology 2009;7(3):98-99. [PubMed: 19507457]

45. Basch E, Iasonos A, Barz A, et al. Long-term toxicity monitoring via electronic patient-reported outcomes in patients receiving chemotherapy. J Clin Oncol 2007;25(34):5374-5380. [PubMed: 18048818]

46. Basch E, Artz D, Iasonos A, et al. Evaluation of an online platform for cancer patient self-reporting of chemotherapy toxicities. J Am Med Inform Assoc 2007;14(3):264-268. [PubMed: 17329732]

47. Liederman EM, Morefield CS. Web messaging: a new tool for patient-physician communication. J Am Med Inform Assoc 2003;10(3):260-270. [PubMed: 12626378]

48. Anhoj J, Moldrup C. Feasibility of collecting diary data from asthma patients through mobile phones and SMS (short message service): response rate analysis and focus group evaluation from a pilot study. Journal of medical Internet research 2004;6(4):e42. [PubMed: 15631966]

49. Bush N, Donaldson G, Moinpour C, et al. Development, feasibility and compliance of a web-based system for very frequent QOL and symptom home self-assessment after hematopoietic stem cell transplantation. Qual Life Res 2005;14(1):77-93. [PubMed: 15789943]

50. Bielli E, Carminati F, La Capra S, Lina M, Brunelli C, Tamburini M. A Wireless Health Outcomes Monitoring System (WHOMS): development and field testing with cancer patients using mobile phones. BMC medical informatics and decision making 2004;4:7. [PubMed: 15196308]

51. Mullen KH, Berry DL, Zierler BK. Computerized symptom and quality-of-life assessment for patients with cancer part II: acceptability and usability. Oncol Nurs Forum 2004;31(5):E84-E89. [PubMed: 15378105]

52. Chang CH. Patient-reported outcomes measurement and management with innovative methodologies and technologies. Qual Life Res 2007;16:157-166. [PubMed: 17530448]

53. Cella D, Yount S, Rothrock N, et al. The Patient-Reported Outcomes Measurement Information System (PROMIS): progress of an NIH Roadmap cooperative group during its first two years. Medical care 2007;45(5 Suppl 1):S3-S11. [PubMed: 17443116]

54. Reeve BB, Hays RD, Bjorner JB, et al. Psychometric evaluation and calibration of health-related quality of life item banks: plans for the Patient-Reported Outcomes Measurement Information System (PROMIS). Medical care 2007;45(5 Suppl 1):S22-S31. [PubMed: 17443115]

55. Patient-Reported Outcomes Measurement Information System: Dynamic tools to measure health outcomes from the patient perspective. National Institutes of Health. [Accessed June 17, 2009]. http://www.nihpromis.org

56. Shekelle, PG.; Morton, SC.; Keeler, EB. Evidence Report/Technology Assessment No. 132. (Prepared by the Southern California Evidence-based Practice Center under Contract No. 290-02-0003.). Rockville, MD: Agency for Healthcare Research and Quality; 2006 Apr. Costs and Benefits of Health Information Technology. Report No.: AHRQ Publication No.06-E006 
57. DesRoches CM, Campbell EG, Rao SR, et al. Electronic health records in ambulatory care--a national survey of physicians. N EnglJ Med 2008;359(1):50-60. [PubMed: 18565855] 


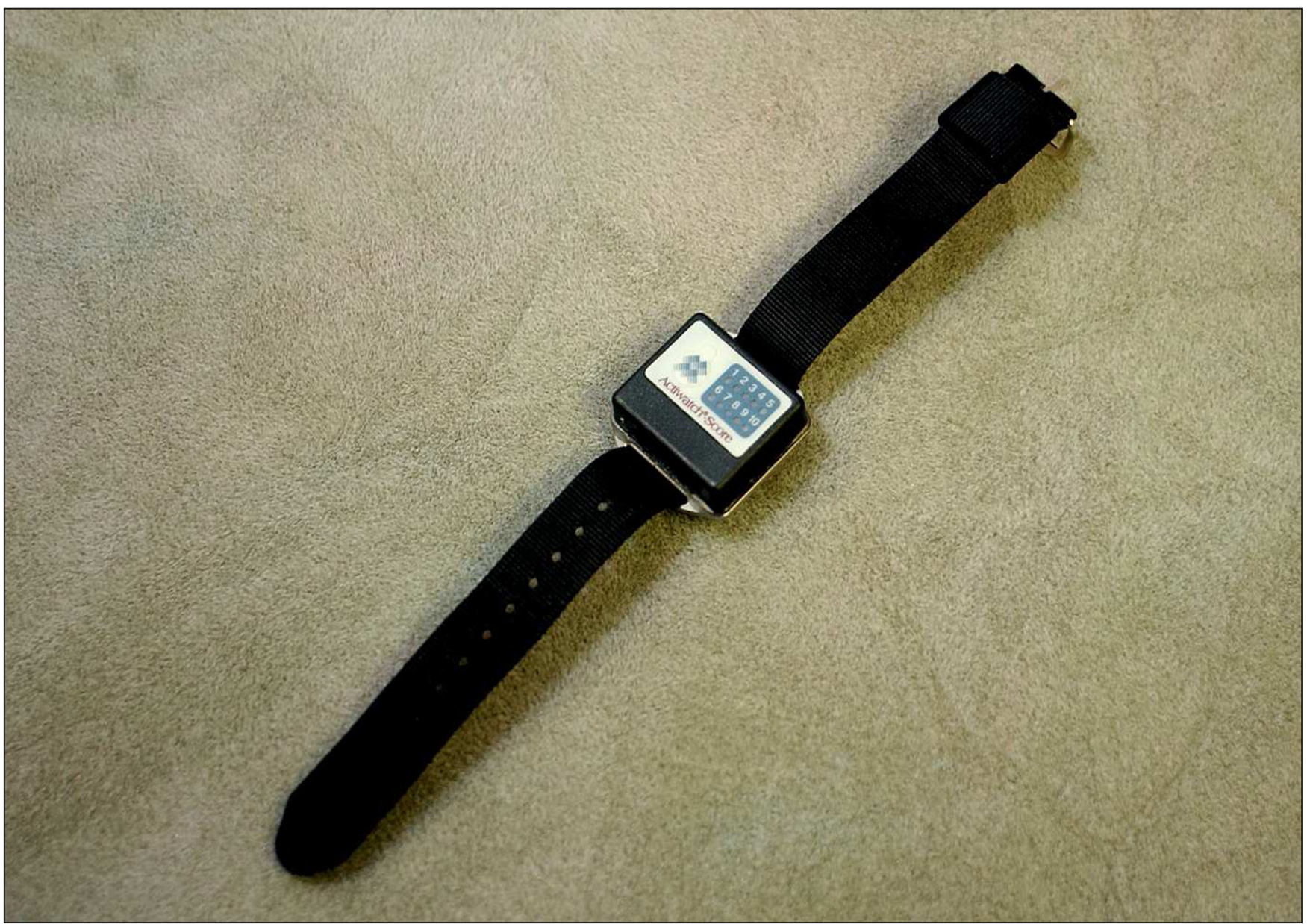

Figure 1.

Subjective Event Marker of the Actiwatch-Score ${ }^{\circledR}$ 
Table 1

Optimal Uses/Benefits and Limitations of Telephone-, Computer-, and Web/Internet-Based Technologies to Assess Quality of Life Outcomes

\begin{tabular}{|c|c|c|}
\hline & Optimal Uses/Benefits & Limitations \\
\hline \multirow{13}{*}{$\begin{array}{l}\text { Commonalities } \\
\text { among Telephone-, } \\
\text { Computer-, and } \\
\text { Web/Internet Based } \\
\text { Technologies }\end{array}$} & Ability to choose formatting for the delivery of questions & High start-up costs. \\
\hline & Ability to collate, organize and analyze the data. & Breach of confidentiality. \\
\hline & Ability to collect data in real-time. & High start-up cost. \\
\hline & Allows branching of questions based on responses. & Local computer malfunction. \\
\hline & Alert systems available & \multirow{9}{*}{$\begin{array}{l}\text { Time and lack of resources may be barriers to } \\
\text { implementation. }\end{array}$} \\
\hline & Customization of instruments available. & \\
\hline & $\begin{array}{l}\text { May be suitable for collecting sensitive information by } \\
\text { reducing observer effects. }\end{array}$ & \\
\hline & Multiple languages available. & \\
\hline & Potentially reduces missing responses. & \\
\hline & Potentially reduces need for human resources. & \\
\hline & $\begin{array}{l}\text { Potentially reduces cost associated with paper or } \\
\text { interviewer-administered questionnaires }\end{array}$ & \\
\hline & $\begin{array}{l}\text { Quality control of data with fewer manual data entry } \\
\text { errors. }\end{array}$ & \\
\hline & Reminder options available. & \\
\hline \multicolumn{3}{|l|}{$\underline{\text { Unique Features }}$} \\
\hline \multirow{6}{*}{$\begin{array}{l}\text { Telephone-Based } \\
\text { Technology }\end{array}$} & Americans very familiar with the technology. & Lack of visual cues for questions and responses. \\
\hline & Appropriate for people with low literacy. & Overexposure to technology in every day life may \\
\hline & Available 24/7. & Ase \\
\hline & Ideal for large clinical trials. & Wordy response formats may impede understanding. \\
\hline & $\begin{array}{l}\text { May be accessed through any telephone system (land-line } \\
\text { or cellular). }\end{array}$ & \\
\hline & Most people have access to a telephone. & \\
\hline \multirow[t]{3}{*}{$\begin{array}{l}\text { Computer-Based } \\
\text { Technology }\end{array}$} & $\begin{array}{l}\text { Administration may include audio, in addition, to video } \\
\text { component. }\end{array}$ & $\begin{array}{l}\text { Administration of QOL questionnaire only available } \\
\text { on designated computer devices. }\end{array}$ \\
\hline & $\begin{array}{l}\text { Maybe available } 24 / 7 \text { only if individual given the } \\
\text { computer device. }\end{array}$ & Storage capacities of some devices may be limited. \\
\hline & Multiple options for choice of computer device. & \\
\hline \multirow[t]{5}{*}{$\begin{array}{l}\text { Web/Internet-Based } \\
\text { Technology }\end{array}$} & $\begin{array}{l}\text { Administration may include audio, in addition, to video } \\
\text { component. }\end{array}$ & $\begin{array}{l}\text { Requires access to a computer device. } \\
\text { Requires access to the Internet. }\end{array}$ \\
\hline & Available 24/7. & \\
\hline & Ideal for large clinical trials. & \\
\hline & May be accessed through any Internet-ready device. & \\
\hline & $\begin{array}{l}\text { Multiple options for choice of Internet-ready computer } \\
\text { device. }\end{array}$ & \\
\hline
\end{tabular}


Table 2

Example Interactive Voice Response Scripts for Quality of Life Assessment

\begin{tabular}{|c|c|}
\hline $\begin{array}{l}\text { Example of an IVR script for QOL } \\
\text { questionnaire using numerical rating } \\
\text { scale. }\end{array}$ & $\begin{array}{l}\text { Example of an IVR script for QOL } \\
\text { questionnaire using combination } \\
\text { number/word responses. }\end{array}$ \\
\hline $\begin{array}{l}\text { On a scale of } 0 \text { to } 10 \text {, how would you rate } \\
\text { your overall health status with } 0 \text { being the } \\
\text { worst possible health and } 10 \text { being the best } \\
\text { possible health? Please enter your rating } \\
\text { now. }\end{array}$ & $\begin{array}{l}\text { In general, how would you rate your } \\
\text { overall health status? } \\
\text { Press } 1 \text { for Excellent. } \\
\text { Press } 2 \text { for Very Good. } \\
\text { Press } 3 \text { for Good. } \\
\text { Press } 4 \text { for Fair. } \\
\text { Press } 5 \text { for Poor }\end{array}$ \\
\hline $\begin{array}{l}\text { On a scale of } 0 \text { to } 10, \text { how would you rate } \\
\text { your overall quality of life with } 0 \text { being the } \\
\text { worse possible quality of life and } 10 \text { being } \\
\text { the best quality of life? Please enter your } \\
\text { rating now. }\end{array}$ & $\begin{array}{l}\text { In general, how would you rate your } \\
\text { overall quality of life? } \\
\text { Press } 1 \text { for Excellent. } \\
\text { Press } 2 \text { for Very Good. } \\
\text { Press } 3 \text { for Good. } \\
\text { Press } 4 \text { for Fair. } \\
\text { Press } 5 \text { for Poor }\end{array}$ \\
\hline
\end{tabular}


Table 3

Instruments Available through Patient-Reported Outcomes Measurement Information System (PROMIS).

\begin{tabular}{l}
\hline Instruments Available as of April 1, 2008 \\
\hline Emotional Distress-Anger \\
Emotional Distress-Anxiety \\
Emotional Distress-Depression \\
Fatigue \\
Pain-Behavior \\
Pain-Impact \\
Physical Function \\
Satisfaction with Discretionary Social Activities \\
Satisfaction with Social Roles \\
Sleep Disturbance \\
Wake Disturbance \\
Global Health
\end{tabular}

Note: All instruments available in computerized format (Item Bank) or pen and paper Short Form. 
Table 4

Helpful Hints for Patients when Browsing the Internet for Cancer Information.

\section{Helpful Hints}

The Internet is a wonderful source of information. Unfortunately, misinformation is also plentiful.

Visit reputable sites when browsing the Internet for cancer information such as the American Cancer Society, National Institutes of Health, National Cancer Institute, Leukemia and Lymphoma Society.

Not all cancers are the same. Treatment for one type of cancer and/or side effect of cancer/cancer treatment may not be appropriate for other types.

Be leery of unsubstantiated claims regarding cancer treatment. Always discuss alternative treatments touted on the Internet with health care provider first.

Discuss findings obtained from the Internet with a health care professional

Be careful about revealing too much personal information. Reputable sites will not ask for confidential information such as social security numbers or private medical information.

Many chat rooms, blogs, social networking sites, etc. are not monitored by a health care professional. Incorrect information may be posted.

Chat rooms, blogs, social networking sites may be a source of support. However, not everyone on these sites may have your best interests at heart.

Internet chat rooms, etc., offer a certain degree of anonymity allowing people to share and/or ask questions about sensitive information. Remember that not everyone is who they say they are! Unsavory characters are looking for vulnerable people.

Internet support groups, while helpful to many, may not be adequate for replacing inperson support available from family and friends.

Be weary of cyberbullying. It can occur even on cancer support sites. 